\title{
An Archeomagnetic Example of Polyphase Magnetization
}

\author{
Michael E. EvANS ${ }^{1}$ and Marianne MARESCHAL ${ }^{2}$ \\ ${ }^{1}$ Institute of Earth and Planetary Physics, Department of Physics, University of Alberta, Edmonton, \\ Alberta, Canada T6G $2 \mathrm{JI}$ \\ ${ }^{2}$ Centre Géologique et Géophysique, Université des Sciences et Techniques du Languedoc, \\ Montpellier, France
}

(Received December 11, 1985; Revised April 30, 1986)

\begin{abstract}
An unusual archeological example of multiple heating leading to superimposed thermoremanent magnetizations (TRM's) is described. The samples involved are roof-tiles which have been incorporated into the floor of a 6th century A.D. kitchen oven at a site near Potenza in southern Italy. Up to $300^{\circ} \mathrm{C}$, thermal demagnetization reveals a pattern of diverging great circles which is interpreted as a "cooking" overprint; $100-300^{\circ} \mathrm{C}$ vector differences yield $D=000^{\circ}, I=+55^{\circ}, k=81$. Above $500^{\circ} \mathrm{C}$ stable "end-points" are obtained and a statistical argument strongly suggests that these represent a TRM acquired when the tiles were originally kiln-fired. A third, intermediate-temperature, component is present, but its origin is unclear. It cannot be an unresolved mixture of the other two, and it is not spatially organized in any obvious manner-we suggest that it was acquired when the tiles were involved in a fire. Thus it appears that quite complicated magnetic histories can be recorded by, and recovered from, archeological materials.
\end{abstract}

\section{Introduction}

Geological samples used in paleomagnetic investigations commonly possess several distinct components of magnetization, reflecting the history of the particular formation involved. On the other hand, fired archeological material is generally much less complicated - a single original thermoremanent magnetization (TRM) with, perhaps, a small recently-acquired viscous remanence (VRM) being the norm. This contrast is not surprising since archeological remains are much younger than the vast majority of geological materials and have therefore not suffered the rigours of deep burial and uplift, heating caused by the emplacement of nearby intrusions, or protracted exposure to weathering. Nevertheless, circumstances can arise in which archeological samples may acquire polyphase remanence, although very few cases have been reported in detail. It is of interest to see how effectively the various magnetic components can be isolated from one another, and to what extent they can be interpreted in terms of the history of this type material. 


\section{Experimental Details}

The archeological feature in question was studied as part of a broader archeomagnetic survey of several sites in southern Italy. It is a kitchen oven of simple design and construction, of which only the floor remains. This is roughly circular in plan with a diameter of about one meter, and consists of tile fragments of irregular shape with typical dimensions of 10 to $20 \mathrm{~cm}$. There is no inferior fire chamber as is found in ancient kilns; the fire seems to have rested directly on the oven floor with the food to be cooked placed at a suitable distance. It was excavated by the University of Alberta Classics Department during investigation of a site located at $40^{\circ} 38^{\prime} \mathrm{N}$, $15^{\circ} 48^{\prime} \mathrm{E}$, near the town of Potenza. The Italian authorities kindly allowed us to remove ten small fragments, each about $10 \mathrm{~cm} \times 10 \mathrm{~cm}$. These were orientated by solar compass and clinometer and from them, $25 \mathrm{~mm}$ diameter cylinders were drilled in the laboratory. Remanence measurements were made with a Digico spinner magnetometer and thermal demagnetization was carried out in a non-inductively wound furnace located in a mumetal-shielded room.

The natural remanent magnetization (NRM) directions are scattered (Table 1, Fig. 1(a)), but step-wise thermal demagnetization up to $300^{\circ} \mathrm{C}$ reveals a clear pattern of diverging great circle trajectories (Fig. 1(b)). Beyond $300^{\circ} \mathrm{C}$ there is an abrupt change of slope in the thermal decay curves (Fig. 2), accompanied by very little or no further directional change up to $450^{\circ} \mathrm{C}$. Between 450 and $500^{\circ} \mathrm{C}$ all samples suffer a rapid drop in intensity and a shift to a new direction. Generally this shift is small -10 to $20^{\circ}$ - but some samples, notably tile 7 , exhibit a change of more than $90^{\circ}$. Hereafter a further stable direction is maintained by all samples, at least until $560^{\circ} \mathrm{C}$,

Table 1. Summary of the various magnetic components.

\begin{tabular}{ccrcccccc}
\hline$(1)$ & $(2)$ & & $(3)$ & $(4)$ & $(5)$ & $(6)$ & $(7)$ \\
Tile & $D, I$ & \multicolumn{1}{c}{$M$} & \multicolumn{1}{c}{$D, I$} & \multicolumn{1}{c}{$D, I$} & $D, I$ & \multicolumn{1}{c}{$k$} & \multicolumn{1}{c}{$D, I$} & $\delta$ \\
\hline 1 & $266,+88$ & 3.4 & $015,+68$ & $109,+02$ & $205,+67$ & 2500 & $186,+70$ & 51 \\
2 & $350,+38$ & 13.4 & $017,+64$ & $240,+20$ & $335,+14$ & 455 & $327,+23$ & 28 \\
3 & $095,+25$ & 15.3 & $358,+54$ & $200,+28$ & $114,-08$ & 3333 & $105,+07$ & 28 \\
4 & $326,+30$ & 12.7 & $351,+51$ & $251,+30$ & $307,+01$ & 789 & $312,+25$ & 17 \\
5 & $339,+64$ & 3.2 & $358,+53$ & $125,+25$ & $267,+55$ & 330 & $269,+81$ & 29 \\
6 & $187,+43$ & 10.8 & $010,+65$ & $276,+08$ & $187,-06$ & 732 & $182,+31$ & 21 \\
7 & $343,+61$ & 47.0 & $351,+49$ & $095,+10$ & $341,+68$ & 12508 & $343,+65$ & 24 \\
8 & $018,+44$ & 18.7 & $000,+47$ & $165,+49$ & $029,+39$ & 4202 & $038,+47$ & 19 \\
9 & $325,+60$ & 4.4 & $357,+52$ & $137,+30$ & $241,+25$ & 265 & $244,+27$ & 11 \\
10 & $125,+58$ & 13.0 & $359,+48$ & $255,+30$ & $136,+02$ & 105 & $120,+19$ & 23 \\
\hline
\end{tabular}

Note: $D$ is measured clockwise from North, $I$ is measured from the horizontal (positive downwards); both in degrees. $M$ is magnetic moment $\left(\mu \mathrm{Am}^{2}\right) . k$ is Fisher's precision parameter. Columns give the following data: (2) NRM. (3) $100-300^{\circ} \mathrm{C}$ vector differences. (4) Poles to demagnetization great circles. (5) Unit-weight vector averages of the $300,350,400$ and $450^{\circ} \mathrm{C}$ treatments. (6) $450-500^{\circ} \mathrm{C}$ vector differences. (7) Acute angle ( $\delta$, in degrees) between the " $\mathrm{C}$ " component and the plane of each tile. 


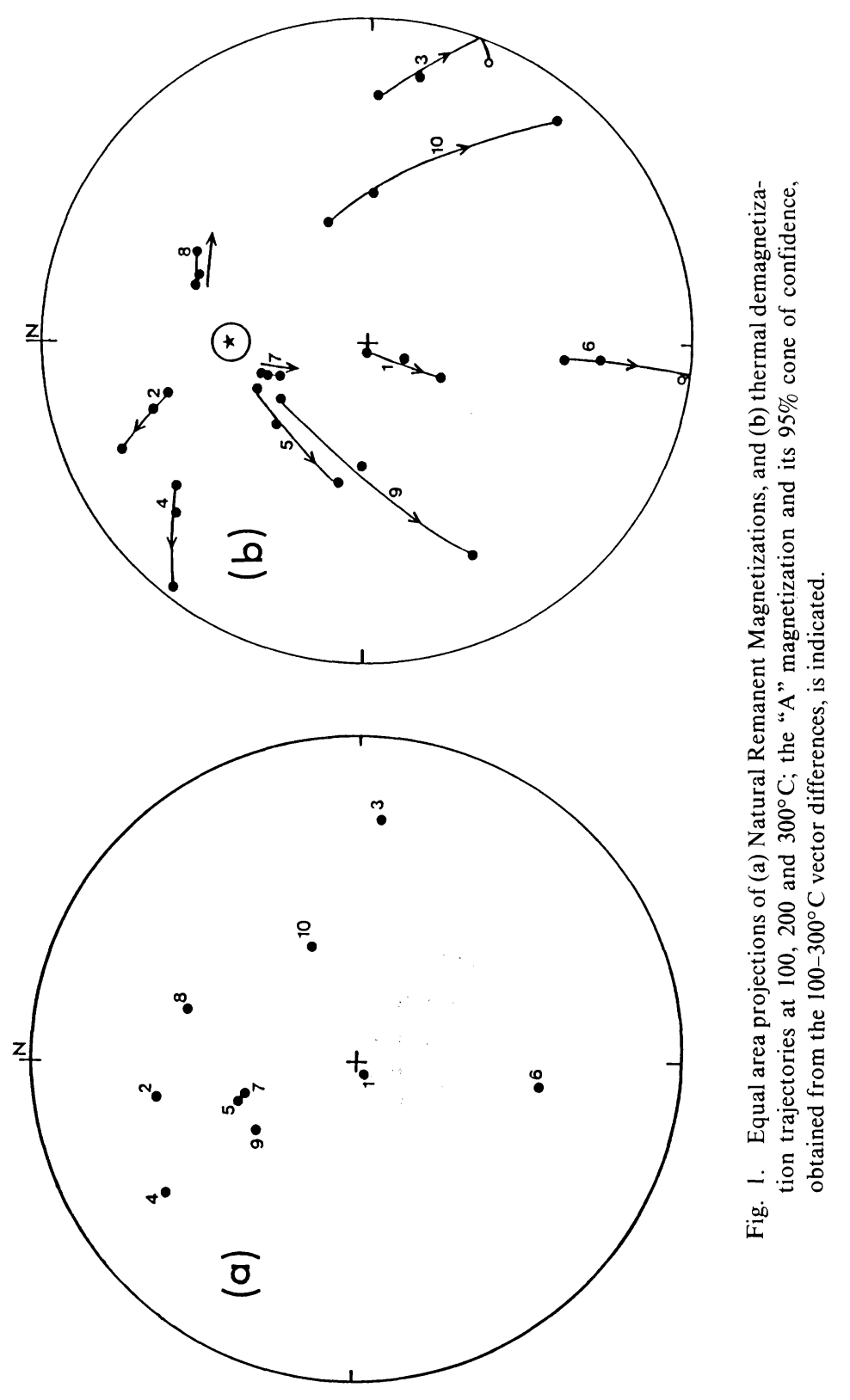




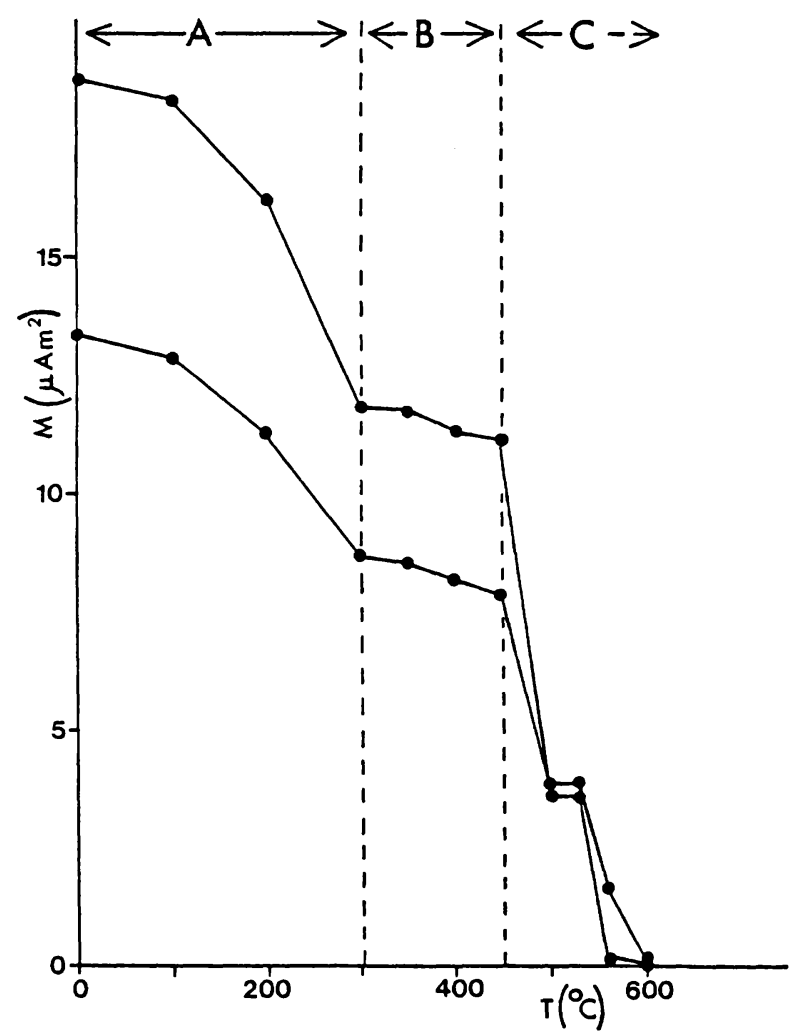

Fig. 2. Typical intensity behaviour during thermal demagnetization (Tiles 2 and 8 ). $M=$ magnetic moment, $T=$ temperature.

and in some cases up to $660^{\circ} \mathrm{C}$. At $690^{\circ} \mathrm{C}$ large, apparently random, angular shifts take place and no sample retains a remanence in excess of $0.6 \%$ of the original NRM. The overall pattern, then, is one of initial movement away from a common origin, followed by two successive stable "end-points" each of which is terminated by rapid intensity and directional changes. Table 1 provides a summary of the individual behaviour of each sample.

\section{Discussion}

It is convenient to refer to the there segments labelled $\mathrm{A}, \mathrm{B}$ and $\mathrm{C}$ in Fig. 2. Segment A corresponds to the diverging great circle trajectories shown on Fig. 1(b). Orthogonal component (Zijderveld) plots indicate that this segment consists of only 3 points $\left(100,200\right.$ and $\left.300^{\circ} \mathrm{C}\right)$; between room temperature and $100^{\circ} \mathrm{C}$ small components, presumably of recent origin, are removed (Fig. 3). The 100 to $300^{\circ} \mathrm{C}$ difference vectors are given in Table 1 . They are well-grouped around a mean 


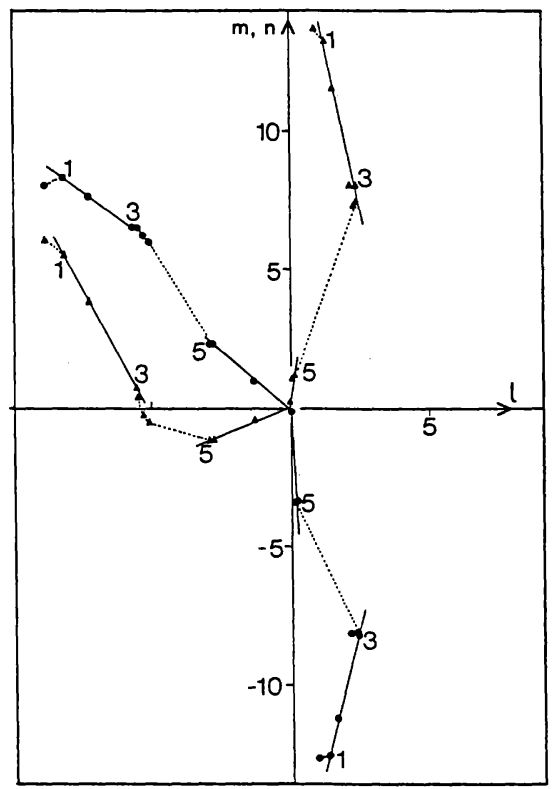

Fig. 3. Orthogonal vector component plots for the two samples of Fig. 2. Data for tile 2 fall to the left of the ordinate, those for tile 8 to the right. The axes $(l, m, n)$ represent arbitrary reference frames fixed to each sample. This avoids the inevitable overlapping (and confusion) present on the re-oriented (North, East, Down) plots. Dots are in the lm plane, triangles in the ln plane. Solid lines represent the " $A$ " and "C" magnetizations (see text), but the dotted connecting lines do not represent specific components of magnetization. Units are $\mu \mathrm{Am}^{2}$. Temperature steps are: room temperature, $100(=1), 200,300(=3)$, $350,400,450,500(=5), 530$ and $560^{\circ} \mathrm{C}$.

direction of $D=000^{\circ}, I=+55^{\circ}\left(k=81, \alpha_{95}=4.9^{\circ}\right)$. A statistically indistinguishable result is obtained from the intersecting great circles method of BAILEY and HALLS (1984) $\left(D=003^{\circ}, I=+52^{\circ}, k=61, \alpha_{95}=5.7^{\circ}\right)$. There can be little doubt that this "A" component is a TRM related to the normal use of the oven, most foods being cooked at temperatures of $250^{\circ} \mathrm{C}$ or less. Furthermore, although there is no comparable Italian data, the results of KOVACHEVA (1980) indicate that the contemporary field in Bulgaria, some $800 \mathrm{~km}$ away, was directed along $D=001^{\circ}, I=+59^{\circ}$. Allowing for the difference in latitude of the two sites, on the basis of a dipolar field, reduces the Bulgarian inclination to $+57^{\circ}$, which lies within the $95 \%$ confidence cone of the " $A$ " magnetization. Bearing in mind the spatial and temporal complexities of the secular variation, this agreement is satisfactory.

It is convenient at this point to turn to segment $C$. End-points represented by the vectors remaining after 500,530 and $560^{\circ}$ are well-defined, with $92<k<2989$. The bulk of this component, however, has blocking temperatures between 530 and $560^{\circ} \mathrm{C}$ (Fig. 2) and most likely resides in magnetite or maghemite. Some samples retain a weak, but stable, remanence up to $660^{\circ} \mathrm{C}$, suggesting the presence of a small hematite contribution. The statistical test devised by WATSON (1956) indicates that, in present 
coordinates, the observed " $\mathrm{C}$ " vectors are randomly scattered $(R=4.03, k=1.51)$. However, closer inspection reveals that it is the declinations which are highly dispersed; the inclinations are mostly quite shallow. In 9 of the 10 cases, the acute angle $(\delta)$ between " $\mathrm{C}$ " and the plane of the corresponding tile lies in the narrow range of $11^{\circ}$ to $29^{\circ}$ (Table 1 ). The probability of a random vector falling between these limits is $0.294\left(=\sin 29^{\circ}-\sin 11^{\circ}\right)$ and thus the probability of obtaining the observed distribution purely by chance is $0.294^{9} \times 0.706 \approx 10^{-5}$. One is therefore compelled to infer some spatial organization. The simplest proposal is that the " $\mathrm{C}$ " magnetization represents a TRM acquired when the tiles were originally fired, and that they were stacked in the kiln in an orderly manner. If, as GOULPEAU and LANGOUET (1982) have demonstrated, most ancient tiles were fired vertically, and if the ambient field at the time was inclined about $55^{\circ}$ below the horizontal, then the angle between TRM and tile would lie between zero and $35^{\circ}$, depending on azimuth (zero for $\mathrm{N}-\mathrm{S}$ tiles, $35^{\circ}$ for $\mathrm{E}-\mathrm{W}$ tiles). The single exception (tile 1 ) has a corresponding angle of $51^{\circ}$ and thus appears to have been fired horizontally, in keeping with the observation that horizontal layers of tiles were used to separate vertical stacks (GOULPEAU and LANGOUET, 1982).

Finally, we turn to segment B, which is more difficult to interpret. The four vectors obtained after $300,350,400$ and $450^{\circ} \mathrm{C}$ are well-grouped, with $105<k<12508$ (Table 1). Of course, these "end-points" do not represent an isolated " $\mathrm{B}$ " component; they are composite due to the presence of the underlying "C" component. Nor can they be interpreted as a combination of " $A$ " and " $C$ " (however that might arise) since they are not, in general, co-planar with them. Since the bulk of the magnetism in this segment is unblocked between 450 and $500^{\circ} \mathrm{C}$ it is natural to ask if the vectors removed between these two treatments are systematically organized in some way. However, they exhibit no grouping in the present frame, and their inclinations are spread evenly between $7^{\circ}$ and $81^{\circ}$ (Table 1 ). Of course, they may not represent a discrete magnetic component at all. But the thermal demagnetization behaviour suggests that all the tiles were heated to a well-defined temperature at some time which pre-dates the construction of the oven in its present form, and post-dates the original kiln firing. Perhaps they were involved in an accidental fire.

\section{Conclusions}

It appears that complex polyphase magnetism sometimes occurs in fired archeological material, and that detailed investigation can-at least under favourable circumstances-lead to an interpretation in terms of realistic historical events. In the example of the tile fragments described here, three distinct TRM's seem to be present. One, which is thermally unblocked above $500^{\circ} \mathrm{C}$, can be attributed to the original kiln firing. A second, which is destroyed entirely below $300^{\circ} \mathrm{C}$, results from everyday cooking while the tiles formed the floor of a kitchen oven. The third is mostly unblocked between 450 and $500^{\circ} \mathrm{C}$ and cannot be convincingly explained; the present evidence suggests that a third heating, perhaps caused by an accidental fire, was involved. 
We are grateful to the Soprintendenza Archeologica della Basilicata for allowing us to remove the samples. We thank Alistair Small and Bob Buck for archeological guidance, Henry Halls and Dick Bailey for providing their computer program and Gerry Hoye for helpful discussions. We thank Hidetoshi Shibuya for a critical review which helped refine the original ms. This work was supported by a grant from the Natural Sciences and Engineering Research Council of Canada.

\section{REFERENCES}

Bailey, R. C. and H. C. Halls, Estimate of confidence in paleomagnetic directions derived from mixed remagnetization circle and direct observational data, J. Geophys., 54, 174-182, 1984.

Goulpeau, L. and L. Langouet, Problems of interpretation of different graphs, I- $\Delta$ obtained through an archeomagnetic study of displaced materials, in Proc. 22nd Sym. Archeometry, pp. 112-121, Univ. of Bradford, 1982.

Kovacheva, M., Summarized results of the archeomagnetic investigation of the geomagnetic field variation for the last 8,000 yr in south-eastern Europe, Geophys. J. R. Astron. Soc., 61, 57-64, 1980.

Watson, G. S., A test for randomness of directions, Mon. Not. R. Astron. Soc., Geophys. Supp., 7, 160-161, 1956. 